\title{
Reseña del libro Sapiens. De animales a dioses. Una breve historia de la humanidad de Yuval Noah Harari (2014)*
}

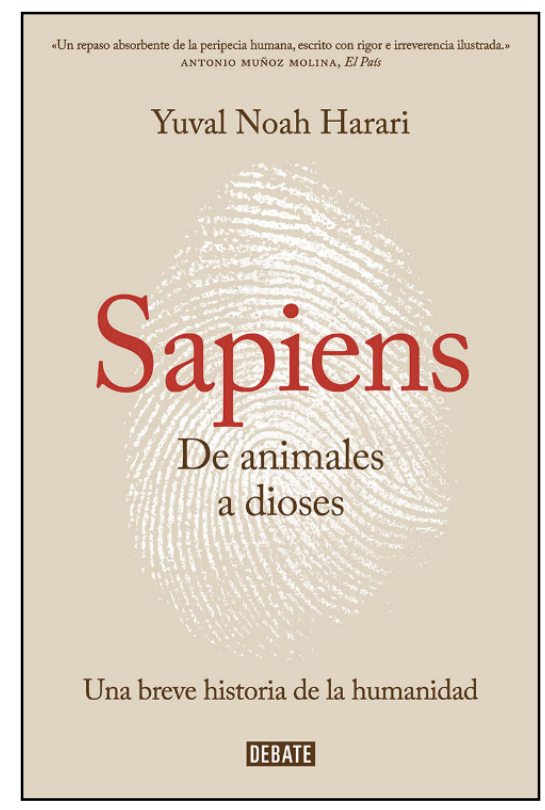

Portada del libro Sapiens. De animales a dioses. Una breve historia de la humanidad Fuente: Harari (2014).

\author{
Claudia Arcila Rojas \\ Universidad de Antioquia, Medellín, Colombia \\ claudiarbol@gmail.com \\ http://orcid.org/0000-0003-4621-0866 \\ María Camila Arcila Rojas \\ Universidad Eafit, Medellín, Colombia \\ cami.arcila9810@gmail.com
}

Cómo citar: Arcila Rojas, C. y Arcila Rojas, M. C. (2021). Reseña del libro Sapiens. De animales a dioses. Una breve historia de la humanidad de Yuval Noah Harari (2014). Ciencias Sociales y Educación, 10(19), 387-391. https://doi.org/10.22395/csye.v10n19a13

Recibido: 10 de febrero de 2021

Aprobado: 25 de febrero de 2021 
Aunque tal vez sea muy ambicioso iniciar este escrito con la intención de responder por qué Yuval Noah Harari habría escrito el libro Sapiens. De animales a dioses. Una breve historia de la humanidad, nos hemos dispuesto a dialogar con nuestras sospechas, intuiciones y riesgos en una especie de intimidad compartida con el texto frente a los mensajes que nos atravesaron y nos sensibilizaron a pensarnos como sujetos en las dinámicas de este mundo moderno, el cual, como lo propone el autor, está dirigido por la ambición en las lógicas del dinero. Con esta premisa decidimos, desde la misión de pensar en la razón de la escritura de este texto, iniciar con la hipótesis de que la intención de Harari es alertarnos frente al tiempo de la globalización y su dominio a través de los imperios. Para el caso de nuestro continente latinoamericano, este dominio no corresponde solamente a los tentáculos de presión que genera el imperio norteamericano a nivel económico. También tiene que ver con la invasión y saqueo por parte del imperio español durante el tiempo de la conquista y al ensombrecimiento de la vida ancestral indígena en nombre de la evangelización y, con ello, al destierro de las prácticas politeístas que impregnaron de divinidad y tolerancia el espacio y el tiempo de relación de los seres humanos con el mundo; al sepultamiento simbólico de rituales y conexiones con el cosmos a través de los códigos de la civilización amparados por la racionalidad instrumental y las gestiones del poder en clave de la rentabilidad y el progreso; al esquema de la democratización como eufemismo para implantar la tiranía y gestionar alianzas estratégicas para la expropiación económica, cultural y política.

Además, coincidimos, desde la experiencia de una lectura y una escritura compartida, en que al autor se le siente el deseo de cuestionar toda enunciación y actitud fanática. Por ello, es crítico frente a las tres grandes religiones del monoteísmo: cristianismo, islamismo y judaísmo, ya que declaran un fundamentalismo de ideas y de comportamientos responsables de grandes ataques a la humanidad en su derecho a la apertura de creencias y prácticas espirituales. En este aspecto es muy fértil la discusión que se asume para vencer las fronteras de la intolerancia y ser capaces de escucharnos con el fin de que las palabras tomen rumbos creativos en medio de la aceptación de la ignorancia y de las acciones que intentan superarla.

Con todo esto, Harari (2014), al explorar la historia de la humanidad a partir del proceso evolutivo de las especies humanas primitivas, desde la edad de piedra hasta el siglo XXI, plantea que la revolución cognitiva como criterio de superioridad obedece a la creación de un lenguaje mítico que despliega las creencias en seres que trascienden la objetividad, como lo son las ideas de deidades, naciones, dinero o derechos humanos. Esto, a su vez, permite el desarrollo de las capacidades para generar asociaciones de manera masiva: religiones, ideologías, sistemas económicos o declaraciones jurídicas y nor- 
mativas. Por esta razón, afirma el autor, el Homo sapiens domina el mundo y experimenta la metamorfosis de animal a dios al creerse una especie superior que es capaz de controlar y dominar las fuerzas de la naturaleza y de todo aquello que pasa a ser sometido y definido como inferior.

De esta manera, De animales a dioses se presenta como un texto que, sospechamos, también pretende ser polémico. En el carácter ficcional de todas estas estructuras, se logra evidenciar una mirada escéptica frente a esta especie pensante que es presentada en una actitud depredadora, comprometida con la extinción de las otras especies arcaicas de género humano, así como de la megafauna original de Australia y América.

Pero para el autor no es suficiente con esta afirmación, sino que también declara su oposición a lo que se entiende como el orden natural de las cosas. En este sentido, indica que todas las jerarquías y divisiones sociales no son más que estructuras de dominio que se han sostenido en el devenir histórico para someter a los señalados como más débiles y a los grupos señalados como poderosos. Este señalamiento indica la elección arbitraria de quienes dominan y son dominados. Es más, implica la autodenominación de los dominantes que se atribuyen el derecho a declarar a los dominados.

Harari (2014) atribuye este estado de cosas a la revolución agrícola que, lejos de mejorar las condiciones de vida de la humanidad, permitió la aparición de sectores complejos de administración de los recursos. Con ello, se dio la división social del trabajo en la implantación binaria de los que administran y los que obedecen.

Bajo este panorama, el autor nos alerta frente a los orígenes de la discriminación y opresión de la población trabajadora, así como de la figura del patriarcado o de la dominación falocéntrica que ha puesto sobre la mujer el yugo de la dominación masculina. Y nos referimos a la nominación de lo masculino porque este yugo también prevalece dentro de nuestra sociedad sobre las diversas manifestaciones femeninas que se marginan de las conductas de la masculinidad impositiva y depredadora. En este sentido, es valioso el llamado de atención del autor al problematizar el orden natural de las cosas, pues las diferentes visiones ideológicas del devenir histórico (esclavismo, feudalismo y capitalismo) se han valido de ese enunciado para aprobar y naturalizar las maquinarias hegemónicas de la opresión.

En este orden de consideraciones sospechamos que la motivación del autor para escribir este libro fue una especie de simpatía con las prácticas vitales de las comunidades de cazadores-recolectores en sus condiciones nómadas. Quizá este hecho permitió que fueran más ligeros de equipaje, de pretensiones 
de posesión y desalojados de ideas dogmáticas tendientes a levantar sectas políticas y económicas. En este sentido, el autor critica los pilares míticos del dinero, los imperios y las religiones que diseñan el mundo de esta modernidad guiada por el antropocentrismo. Esta prevalencia del ser humano indignifica todas las demás manifestaciones de la vida en sus experimentos de domesticar animales, transgenizar semillas, contaminar los elementos de la naturaleza, decretar una condición divina en las sentencias de la revolución científica al crear, a través de la clonación, nuevos espectros de vida, desafiar los límites de nuestro sistema solar y romper su filamento magnético para indagar y posiblemente invadir otros universos planetarios.

De cualquier manera, sentimos que Yuval Noah Harari escribió este libro para invitarnos a abandonar toda pretensión de verdades absolutas, tanto provenientes de la ciencia como de la religión y sus réplicas en estructuras políticas y económicas. No hay verdades absolutas que puedan llevarnos incluso a creer que todo lo que él ha plasmado en su escritura pueda ser asumido como tal. Aunque en este punto las apreciaciones son divergentes, fundamentalmente en la valoración de las mascotas como aliadas de una cotidianidad en la que se tejen lazos de compañía y, por otro lado, como víctimas de nuestra voluntad de someter a criterios de humanización el sentir y expresar de los animales, coincidimos en que el amor a los animales es una manifestación de aprobación de la vida, una memoria de conexión con el cosmos y con todo su despliegue de grandeza.

Además, nos cuesta creer que la naturaleza sea un escenario de barbarie en el cual no podemos consentir ni comprender la posibilidad del ethos como aliento vital que nos vincula a una relación ética con la existencia. La naturaleza es, y en esto coincidimos sin ningún asomo de duda, el reflejo del cosmos que, aún con sus misterios, nos sumerge en la armonía de la belleza, que no puede ser contraria a las expresiones de su propia condición dinámica. Es una armonía que también se expresa en las tormentas y calamidades, porque tampoco la belleza es absoluta en su sentido de lo estático. Entonces, al estar en la permanencia del cambio, asumimos que el autor, con cierta sagacidad y agudeza literaria, se propone trazar, a través del vasto acumulado de páginas de su libro, un gesto de ironía con esta modernidad en la cual todos, de una u otra manera, pretendemos ser dioses, emperadores y conquistadores de verdades tan frágiles como nosotros mismos. Lo cierto de la permanencia del movimiento es que estamos de cara a la fragilidad, al desgaste y a lo renovado. La materia es movida por la energía, y esta no nace ni muere, sino que se transforma. La energía intelectual de este texto también es un lenguaje de transformación donde el mismo autor es un artista coloreando sus pensamientos. Esto es lo que creemos que motivó la gran obra que hemos tenido el placer de leer y de cuestionar en una experiencia polifónica, donde el discurso oral y escrito nos puso en el reto 
de tejer emociones y pensamientos a través de esta fotografía del lenguaje. Es una obra que nos hizo sonreír al sentirnos sintonizadas con muchos de sus postulados, pero también cuando nos resistimos a algunos de sus postulados, tal vez como mecanismo de defensa a muchas afirmaciones que nos impulsaron a trazar e insinuar gestos de acusación y de culpa. Amar los animales en la defensa de su libertad y mientras los sentimos parte de nuestra familia fue un aspecto de acalorada discusión que decidimos ponerlo en el dinamismo de la escritura como dos rutas semánticas que, en ninguno de los casos, pretende negar el derecho a estas concepciones.

Resonar con la idea de indignificar la vida de los animales en la interioridad de un hogar, que restringe la expresividad instintiva de estos seres, hace válido narrar otra visión desde el sentir de una experiencia diferente en la convicción de amar a las mascotas y entregarles la más sincera expresión del cuidado. Sería hipócrita dejar en blanco este apartado cuando se tiene la alegría de compartir con un par de gatas a las que nunca he indignificado: un par de parientes espirituales a las que siento como parte de mi historia más remota en reencuentro con este presente.

Nos atrevemos a declarar que este libro, más allá de estas polaridades que pueda suscitar, fue escrito porque es necesario reírnos de todo lo que pretenda posicionarse como verdadero. En esa medida, no hay verdades en este libro ni en ningún otro del cual intentemos reconocer sus razones. La escritura es un movimiento dinámico del pensamiento que ha de llevarnos a la experiencia de una comedia que, por momentos, también dialoga con la tragedia. Y eso es la vida: el movimiento maravilloso del reír y del llorar para poder escuchar el canto que anuncia tanto nuestro nacer como nuestro morir para dar lugar a una posible nueva aparición en la existencia. Este devenir de la vida renovada será razón, tal vez, de otro movimiento de la escritura. Por ahora creemos suficiente el análisis de razones que movieron a Yuval Noah Harari a escribir Sapiens. De animales a dioses. Una breve historia de la humanidad.

\section{Referencias}

Harari, Y. (2014). Sapiens. De animales a dioses. Una breve historia de la humanidad. Debate. 